\title{
High-dose intravenous immunoglobulin therapy in multifocal motor neuropathy
}

\author{
E. Nobile-Orazio, MD, $\mathrm{PhD} ;$ N. Meucci, MD; S. Barbieri, MD, PhD; M. Carpo, MD; and G. Scarlato, MD
}

\begin{abstract}
Article abstract-We treated five consecutive patients with multifocal motor neuropathy (MMN) with high-dose intravenous immunoglobulin (IVIg). Four patients had increased levels of anti-asialo-GM IgM and two of anti-GM $_{1}$ IgM as well; one patient had no reactivity. We treated them twice with $0.4 \mathrm{~g} / \mathrm{kg}$ IVIg for 5 consecutive days at a 2month interval, followed by maintenance infusions up to 6 to 12 months. All patients with high anti-asialo-GM ${ }_{1}$ had a consistent clinical improvement starting 3 to 10 days after the first IVIg course; in one patient, recovery was complete and persistent for 12 months without additional treatment, while in three patients, improvement only lasted 20 to 30 days. There was a similar improvement in these patients after the second course of IVIg which was maintained by periodic 2-day IVIg infusions. Clinical improvement in these patients was associated with a reduction of conduction block in most, but not all, motor nerves, while antibody titers were not consistently modified by treatment. There was no clinical or electrophysiologic improvement in the patient without antiglycolipid activity after 6 months of IVIg. IVIg may be a safe and effective therapy for MMN.
\end{abstract}

NEUROLOGY 1993;43:537-544

Multifocal motor neuropathy (MMN) is characterized by a progressive, predominantly distal, asymmetric limb weakness with conduction block (CB) on motor but not sensory nerves. ${ }^{1-10}$ High levels of serum antibodies to the ganglioside $\mathrm{GM}_{1}$ or to asialo-GM $\mathrm{G}_{1}$ or both, may be present in these patients, ${ }^{1-3,9}$ and in some, improvement was associated with a decrease of anti-GM ${ }_{1}$ levels, ${ }^{2,11}$ suggesting that the disease may be immune mediated.

Patients with MMN do not usually respond to steroids, ${ }^{7-11}$ which may occasionally worsen symptoms (M. Donaghy, unpublished observation), or to plasma exchange, ${ }^{7,9,11}$ but they often improve with high-dose intravenous cyclophosphamide $\left(3 \mathrm{~g} / \mathrm{m}^{2}\right.$ in 8 days). ${ }^{2,9,11}$ This treatment, however, has relevant side effects ${ }^{12,13}$ and may be unsuitable for the less severely affected patients.

High-dose intravenous immunoglobulin (IVIg) therapy has been reported to be effective in some dysimmune neuropathies, including Guillain-Barré syndrome ${ }^{14}$ and chronic inflammatory demyelinating polyneuropathy (CIDP), ${ }^{15-20}$ where improvement was associated with reduction of CB. ${ }^{21}$

We treated five patients with MMN with IVIg therapy for 6 to 12 months. All patients were mildly-to-moderately affected and did not receive additional therapies for the first 3 months.

Methods. Patients. Five consecutive patients with MMN were included in the study. The diagnosis of MMN was made in the presence of clinical and electrophysiologic evidence of an asymmetric motor neuropathy that had been progressive for more than 2 months, without or with only mild sensory loss, with $\mathrm{CB}$ (for definition, see below) in two or more motor nerves excluding the usual sites of nerve compression. ${ }^{1-3}$ Three patients (nos. 2, 3, and 4) had been previously treated with steroids, which had had no effect in two while one (patient 2) had a severe and rapid worsening that almost confined the patient to a wheelchair.

Electrodiagnostic studies. Electrodiagnostic studies were performed in all patients under standard conditions before, during, and after treatment. Needle EMG was performed with concentric needle electrode in proximal and distal muscles of the lower and upper extremities. Motor conduction studies were performed in nerves of the upper (right and left median and ulnar) and lower extremities (right and left peroneal and posterior tibial) using surface electrodes. All the patients were proximally stimulated both at the elbow and at Erb's point. Sensory conduction studies were performed orthodromically in the median and ulnar nerves and antidromically in the sural nerve. $\mathrm{CB}$ in motor nerves was defined as a reduction in the ratio of proximal-to-distal compound muscle action potential

From the Institute of Clinical Neurology, Centro Dino Ferrari, University of Milan, Ospedale Maggiore-Policlinico, Milan, Italy.

Supported by the "Associazione Amici Centro Dino Ferrari," and by a grant from the Associazione Italiana Sclerosi Multipla.

Presented in part at the 44th annual meeting of the American Academy of Neurology, San Diego, CA, May 1992.

Received May 18, 1992. Accepted for publication in final form July 15, 1992.

Address correspondence and reprint requests to Dr. Eduardo Nobile-Orazio, Institute of Clinical Neurology, University of Milan, Via Francesco Sforza 35 , 20122, Milan, Italy. 
Table 1. Clinical features of patients with MMN before intravenous high-dose immunoglobulin therapy

\begin{tabular}{|c|c|c|c|c|c|c|}
\hline \multirow{2}{*}{$\begin{array}{l}\text { Pt } \\
\text { no. }\end{array}$} & \multirow[b]{2}{*}{ Age/Sex } & \multicolumn{5}{|c|}{ Clinical features of neuropathy } \\
\hline & & $\overline{\text { Duration }}$ & Progression & Severity* & Distribution & Sensory loss \\
\hline 1 & $48 / \mathrm{M}$ & $10 \mathrm{yr}$ & Stepwise & 2 & $\mathrm{U}>\mathrm{L}-\mathrm{D}>\mathrm{P}$ & No \\
\hline 2 & $26 / \mathrm{F}$ & $5 \mathrm{yr}$ & Stepwise & 4 & $\mathrm{U}>\mathrm{L}-\mathrm{D}>\mathrm{P}$ & No \\
\hline 3 & $51 / \mathrm{F}$ & $4 \mathrm{yr}$ & Stepwise & 2 & $\mathrm{~L}>\mathrm{U}-\mathrm{D}>\mathrm{P}$ & No \\
\hline 4 & $32 / \mathrm{M}$ & $4 y r$ & Progressive & 3 & $\mathrm{U}>\mathrm{L}-\mathrm{D}=\mathrm{P}$ & Yes \\
\hline 5 & $40 / \mathrm{M}$ & $3 \mathrm{mo}$ & Progressive & 3 & $\mathrm{U}=\mathrm{L}-\mathrm{P}>\mathrm{D}$ & No \\
\hline
\end{tabular}

(CMAP) amplitude to $<0.60$, when the ratio of the proximal-to-distal negative peak duration was $<1.15 .{ }^{11,22,23}$

Antibody studies. Antiglycolipid $\left(\mathrm{GM}_{1}\right.$, asialo- $\mathrm{GM}_{1}$, $\mathrm{GM}_{2}, \mathrm{GD}_{1 \mathrm{a}}, \mathrm{GD}_{1 \mathrm{~b}}$ ) antibodies were measured by ELISA as previously described. ${ }^{24}$ Briefly, wells of ELISA plates were absorbed with $1 \mu \mathrm{g}$ ganglioside (Sigma, St. Louis, MO; except $\mathrm{GM}_{1}$, Fidia, Abano Terme, Italy) or bovine serum albumin (BSA) (Sigma), saturated with BSA, and incubated with patients' serum diluted 1:80 (for $\mathrm{GM}_{1}$, $\mathrm{GM}_{2}, \mathrm{GD}_{1 \mathrm{a}}, \mathrm{GD}_{1 \mathrm{~b}}$ ), or 1:320 (asialo-GM $\mathrm{GM}_{1}$ ), followed by peroxidase-conjugated goat anti-human IgM (Cappel; Durham, NC). The color reaction was developed for 60 minutes and the absorbance measured at $490 \mathrm{~nm}$. Readings from wells coated with BSA were subtracted from wells coated with glycolipids. When the difference exceeded 0.05 , sera were titrated by serial twofold dilution until negative (difference below 0.05). The upper normal limits in our laboratory corresponded to the highest titers obtained from 20 normal subjects and 40 patients with IgM monoclonal gammopathy without neuropathy.

Treatment protocol. All patients were initially treated with IVIg (Sandoglobulin; Sandoz; Basel, Switzerland), $0.4 \mathrm{~g} / \mathrm{kg}$, for 5 consecutive days. The same regimen was repeated in four patients (nos. 1, 2,3, and 4) after 6 to 10 weeks and was followed by a 1- or 2-day infusion $(0.4$ $\mathrm{g} / \mathrm{kg} / \mathrm{d}$ ) every 2 to 4 weeks according to the patient's response. No additional therapy was given to patients during the first 3 to 5 months. Afterward, oral cyclophosphamide $(1.5$ to $3 \mathrm{mg} / \mathrm{kg} / \mathrm{d})$ was added in two patients (nos. 1 and 2) in order to reduce the frequency of maintenance IVIg infusions.

Assessment of response. Clinical response was assessed using (1) the Medical Research Council (MRC) rating scale $^{25}$ for muscle strength; 10 muscles per limb (total 40 ) were examined while improvement was calculated in the 10 most affected muscles in upper and in lower limbs (total 20 muscles, maximal score $=100$ ); (2) a modified Rankin disability scale ${ }^{17}: 0=$ asymptomatic; $1=$ nondisabling symptoms not interfering with lifestyle; $2=$ minor disability symptoms leading to some restriction of lifestyle but not interfering with patients' capacity to look after themselves; $3=$ moderate disability symptoms significantly interfering with lifestyle or preventing totally independent existence; 4 = moderately severe disability symptoms preventing independent existence, although patients do not need constant attention day and night; 5 = severely disabled, totally dependent, requiring constant attention day and night; and (3) a functional impairment scale for both upper and lower limbs (UL/LL) (maximal score: $5+5=10): 0=$ asymptomatic; $1=\mathrm{UL} / \mathrm{LL}$ symptoms without functional impairment (walk normally); $2=$ some minor difficulties in manual activities, which are still possible/abnormal walk but possible without support;
$3=$ unable to perform some manual activities/walk autonomously but with support; 4 = not capable of manual work/need help to walk; $5=$ total paralysis/confined to wheelchair. Patients were examined before (day 0), during (days 1 through 5), and after (days 6, 10, and 30) each IVIg course, then monthly up to 6 months. Additional assessments were performed before and after maintenance infusions. Electrodiagnostic studies were performed on day 0 and day 10 of each IVIg course, and after 2 and 6 months of therapy. Serum Ig and antiglycolipid levels were measured on days 0,6 , and 10 of IVIg course, then monthly up to 6 months or, when performed, before and after each maintenance infusion. A thorough laboratory investigation was performed in all patients before and periodically during IVIg therapy to exclude the presence of concurrent diseases.

Results. The clinical features of the five patients before treatment are summarized in table 1. All patients had asymmetric limb weakness, more prominent distally in three, with arms more affected than legs in three. Reflexes were reduced only in affected districts in three patients (nos. 1, 3, and 5) while two (nos. 2 and 4) had generalized areflexia. Cramps were prominent in four (nos. 2, 3, 4, and 5), fasciculations in three (nos. 1, 2, and 5). All but one patient (no. 4) had some degree of muscle wasting that was prominent, although localized to only one arm, in one patient (no. 1). Minor sensory symptoms consisting of limb paresthesias were reported by two patients (nos. 3 and 4), although only one (no. 4) had a slight sensory loss. Before IVIg therapy, all patients were ambulatory with a Rankin score between 2 and 4 (mean, 2.8).

The results of motor and sensory nerve conduction studies in the five patients before treatment are presented in table 2 . All patients had motor CB in two or more nerves, most frequently in the upper limbs. Although some slowing of motor conduction velocities was observed in four patients, a marked reduction $(<70 \%$ or $<80 \%$ of the lower normal limit when the amplitude was $<80 \%$ or $>80 \%$, respectively, of the lower normal limit ${ }^{26}$ was only found in five of 34 nerves tested (the right ulnar and left median nerves of patient 2 and the right and left ulnar and right median nerves of patient 4) and usually corresponded to a segment with marked $\mathrm{CB}$. In these, as in the other nerves with $\mathrm{CB}$, there was no abnormal temporal dispersion and $C B$, 
Table 2. Motor and sensory nerve conduction studies in five patients with MMN before IVIg therapy

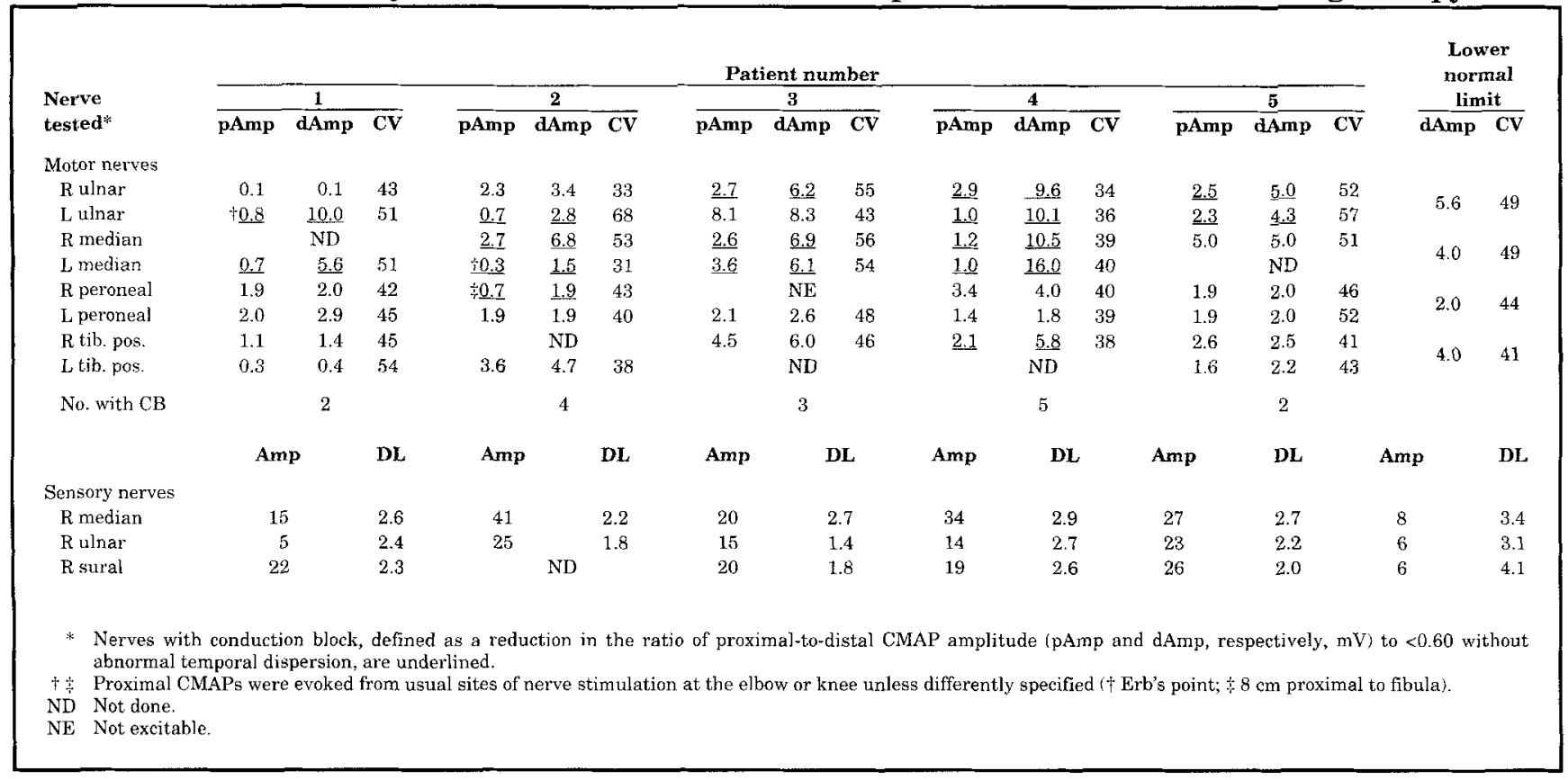

Table 3. Laboratory findings in five patients with MMN before IVIg therapy

\begin{tabular}{|c|c|c|c|c|c|c|c|c|}
\hline \multirow[b]{2}{*}{$\begin{array}{l}\text { Pt } \\
\text { no. }\end{array}$} & \multicolumn{2}{|c|}{ CSF } & \multicolumn{6}{|c|}{ Antiglycolipid antibody titers } \\
\hline & $\begin{array}{c}\text { Cells } \\
\left(\mathbf{n} / \mathbf{m m}^{3}\right)\end{array}$ & $\begin{array}{c}\text { Protein } \\
(\mathrm{mg} / \mathrm{dl})\end{array}$ & $\overline{(I g M)}$ & (IgG) & $\frac{\text { Asialo-GM }}{(\text { IgM) }}$ & $\frac{\mathbf{G D}_{\mathrm{ib}}}{(\mathbf{I g M})}$ & $\frac{\mathbf{G D}_{1 \mathrm{u}}}{(\mathbf{I g} \mathbf{M})}$ & $\frac{\mathbf{G M}_{2}}{(\mathbf{I g M})}$ \\
\hline 1 & 0.5 & $\underline{72} *$ & $\underline{1 / 320}$ & - & $\underline{1 / 1,280}$ & $1 / 80$ & - & $1 / 80$ \\
\hline 2 & 0.7 & 27 & - & - & $\underline{1 / 1,280}$ & - & - & $1 / 80$ \\
\hline 3 & ND & ND & - & - & $\underline{1 / 1,280}$ & $1 / 320$ & - & $1 / 80$ \\
\hline 4 & 0.3 & 36 & - & - & $1 / 320$ & $1 / 80$ & - & $1 / 80$ \\
\hline 5 & 1.6 & $\underline{54}$ & $\underline{1 / 320}$ & - & $\underline{1 / 2,560}$ & $1 / 80$ & $1 / 320$ & $1 / 80$ \\
\hline Normal limits & 5 & 45 & $1 / 80$ & $1 / 320$ & $1 / 640$ & $1 / 320$ & $1 / 320$ & $1 / 320$ \\
\hline $\begin{array}{r}* \text { Values abo } \\
\text { - Negative a } \\
\text { ND Not done. }\end{array}$ & ial serum & $\begin{array}{l}t \text { are under } \\
\text { on of } 1 / 320\end{array}$ & $M_{1}$ ) or & other & osides). & & & \\
\hline
\end{tabular}

when present, could be localized to a circumscribed area, usually 5 to $10 \mathrm{~cm}$ distal to the elbow. Sensory conduction studies were normal in all patients.

CSF was examined in four patients before treatment. CSF proteins were slightly increased in two patients and normal in two, while cells were normal in all (table 3). Anti-asialo-GM 1 IgM levels were moderately increased in four patients, two of whom also had increased levels of anti-GM IgM; $^{-}$ no reactivity was detected in patient 4 (table 3 ).

Sural nerve biopsy ${ }^{27}$ was performed in two patients (nos. 2 and 4 ) before treatment, showing a normal or reduced density of myelinated fibers $\left(5,870\right.$ and $2,737 / \mathrm{mm}^{2}$, respectively; normal range, 5,000 to 7,200 ) with normal teased-fiber studies. ${ }^{28}$ In patient 3 , both the sural nerve and a motor branch of the peroneal nerve were examined and showed a reduced density of myelinated fibers $\left(3,038\right.$ and $2,675 / \mathrm{mm}^{2}$, respectively), with an increased proportion of teased fibers with signs of axonal degeneration (condition $\mathrm{E})(18 \%$ and $7 \%$, respectively; normal, 0 to $5 \%$ ) or of demyelination and remyelination (conditions $\mathrm{C}$ and $\mathrm{D})(47 \%$ and $50 \%$, respectively; normal, $2 \%$ to $24 \%$ ) that in half the fibers was plurisegmental (more than 5 internodes). In none of the nerves were there inflammatory cell infiltrates, amyloid deposits, abnormal blood vessels, or deposits of immunoglobulins. ${ }^{27}$

Response to treatment. The clinical responses to IVIg therapy in the five patients with MMN are summarized in table 4. One patient (no. 5) progressively recovered to normal after the first course of IVIg therapy without relapse in 12 months. This patient first noted some improvement in limb strength on the third day of therapy and reached a normal strength in 5 months without additional therapy. In three patients (nos. 1, 2, and 3), an improvement of at least one grade in the Rankin and limb disability scores was observed starting 3 to 10 days after the first IVIg course but only last- 
Table 4. Clinical response to IVIg in patients with MMN

\begin{tabular}{|c|c|c|c|c|c|c|}
\hline \multirow{2}{*}{$\begin{array}{l}\text { Pt } \\
\text { no. }\end{array}$} & \multicolumn{2}{|c|}{ 1st IVIg course } & \multicolumn{2}{|c|}{ 2nd IVIg course } & \multirow{2}{*}{$\begin{array}{l}\text { At } 6 \mathrm{mo} \\
\text { of therapy }\end{array}$} & \multirow{2}{*}{$\begin{array}{c}\text { Overall } \\
\text { improvement }\end{array}$} \\
\hline & Before & At $10 \mathrm{~d}$ & Before & $\overline{\text { At } 10 \mathrm{~d}}$ & & \\
\hline \multicolumn{7}{|c|}{ Rankin score } \\
\hline 1 & 2 & 1 & 2 & 1 & 1 & +1 \\
\hline 2 & 4 & 3 & 3 & 2 & 2 & +2 \\
\hline 3 & 2 & $2 \cdot 1^{*}$ & 2 & 1 & 1 & +1 \\
\hline 4 & 3 & 3 & 3 & 3 & 3 & 0 \\
\hline 5 & 3 & $3 \cdot 0^{*}$ & \multicolumn{2}{|c|}{$0 \dagger$} & 0 & +3 \\
\hline Mean & 2.8 & $2.4 \rightarrow 1.6^{*}$ & 2.0 & 1.4 & 1.4 & +1.4 米 \\
\hline \multicolumn{7}{|c|}{ Limb impairment score } \\
\hline 1 & 4 & 2 & 4 & 2 & 2 & +2 \\
\hline 2 & 7 & $5 \cdot 4^{*}$ & 5 & 4 & 2 & +5 \\
\hline 3 & 3 & $3 \rightarrow 2^{*}$ & 3 & 2 & 2 & +1 \\
\hline 4 & 5 & 5 & 5 & 5 & 5 & 0 \\
\hline 5 & 5 & $4 \cdot 0^{*}$ & \multicolumn{2}{|c|}{$0 \dagger$} & 0 & +5 \\
\hline Mean & 4.8 & $3.6 \rightarrow 2.6^{*}$ & 3.2 & 2.6 & 2.2 & $+2.6 \$$ \\
\hline \multicolumn{7}{|c|}{ MRC score } \\
\hline 1 & 76 & $86 \rightarrow 92^{*}$ & 76 & 88 & 90 & +14 \\
\hline 2 & 36 & $54+68^{*}$ & 44 & 54 & 80 & +44 \\
\hline 3 & 80 & $84 \rightarrow 86^{*}$ & 80 & 84 & 90 & +10 \\
\hline 4 & 61 & 72 & 66 & 74 & 80 & +19 \\
\hline 5 & 70 & $85 \rightarrow 98^{*}$ & \multicolumn{2}{|c|}{$98 \dagger$} & 100 & +30 \\
\hline Mean & 65 & $76 \rightarrow 83^{*}$ & 73 & 80 & 88 & $+23 \mathbb{I}$ \\
\hline \multicolumn{7}{|c|}{$\begin{array}{l}\text { * Lowest score reached after the } 10 \text { th day, before the second course. } \\
\dagger \text { Second course not performed, score at } 2 \text { months. } \\
\ddagger t \text { (paired): } 2.746 ; p=0.052 \text {. } \\
\S t \text { (paired): } 2.525 ; p=0.065 . \\
\text { ๆ } t \text { (paired): } 3.80 ; p=0.019 .\end{array}$} \\
\hline
\end{tabular}

ed 20 to 30 days. Retreatment after 6 to 10 weeks with the same regimen was followed by a similar improvement that was maintained, depending on the individual patient, with 2-day IVIg infusions $(0.4 \mathrm{~g} / \mathrm{kg} / \mathrm{d})$ every 2 to 4 weeks. In two of these patients (nos. 1 and 2; figure 1), the frequency of maintenance infusions was progressively reduced when oral cyclophosphamide ( 1.5 to $3 \mathrm{mg} / \mathrm{kg} / \mathrm{d}$ ) was given 3 to 5 months after starting IVIg. In one patient (no. 4), no improvement in the Rankin and limb impairment scores was observed after 6 months of IVIg therapy (three courses at 2-month intervals, followed by 1-day infusion every 2 weeks up to 6 months) although the overall MRC score rose from 61 to eighty. The average improvement in the five patients after 6 months of therapy was 1.4 in the Rankin score $(t=2.746 ; p=0.0516), 2.6$ in the limb impairment score $(t=2.525 ; p=0.065)$, and 23 in the MRC score $(t=3.80 ; p=0.019)$. None of the patients had relevant adverse reactions during or after IVIg infusions. Two patients experienced mild headache with moderate fever (less than $38{ }^{\circ} \mathrm{C}$ ) and itching after the first infusion. These symptoms were subsequently controlled with chlorpheniramine maleate.

Electrodiagnostic studies during IVIg therapy (figure 2) showed a complete resolution or a $20 \%$ or more reduction of $\mathrm{CB}$ in eight of 11 motor nerves from the four patients improving with IVIg therapy, while no modification was found in the patient not responding to treatment. A close correlation between reduction of $\mathrm{CB}$ and IVIg therapy was particularly evident in the right peroneal and left ulnar nerves of patient 2 , the right median and ulnar nerves of patient 3 , and both ulnar nerves of patient 5. In the last patient, $C B$ reappeared in the left ulnar nerve after 6 months without concomitant clinical worsening. The improvement of CB in the left median nerve of patient 1 was only evident at 6 months when he was also taking oral cyclophosphamide. In only two nerves (left median of patient 1 and right peroneal of patient 2 ), the reduction of $\mathrm{CB}$ was due to a selective increase of the proximal CMAP amplitude, while in all other nerves a concomitant, although lesser, increase of the distal amplitude was also observed (figure 3). Motor conduction velocities were slightly modified by IVIg therapy in patient 1 but remained unchanged in the other patients.

A transient but inconstant twofold reduction of anti-asialo-GM 1 IgM titers was observed in two patients (nos. 1 and 2) after IVIg. This reduction became stable in one patient (no. 1) 2 months after starting cyclophosphamide. In patient 5 , a twofold reduction of antibody levels was observed after the initial IVIg course and was still evident at 6 
Patient No. 1

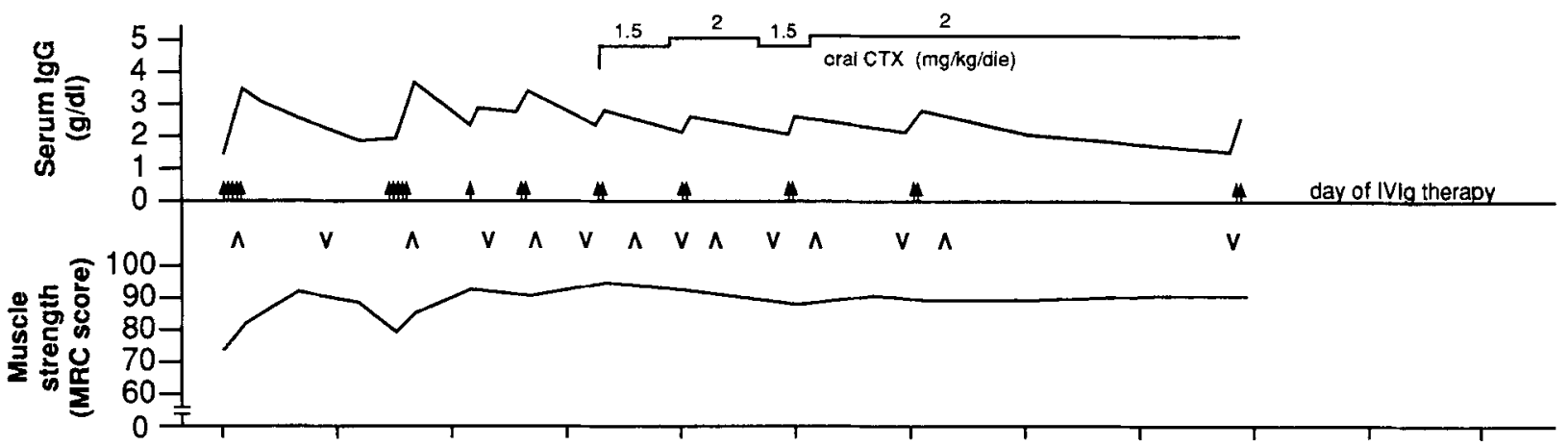

Patient No. 2

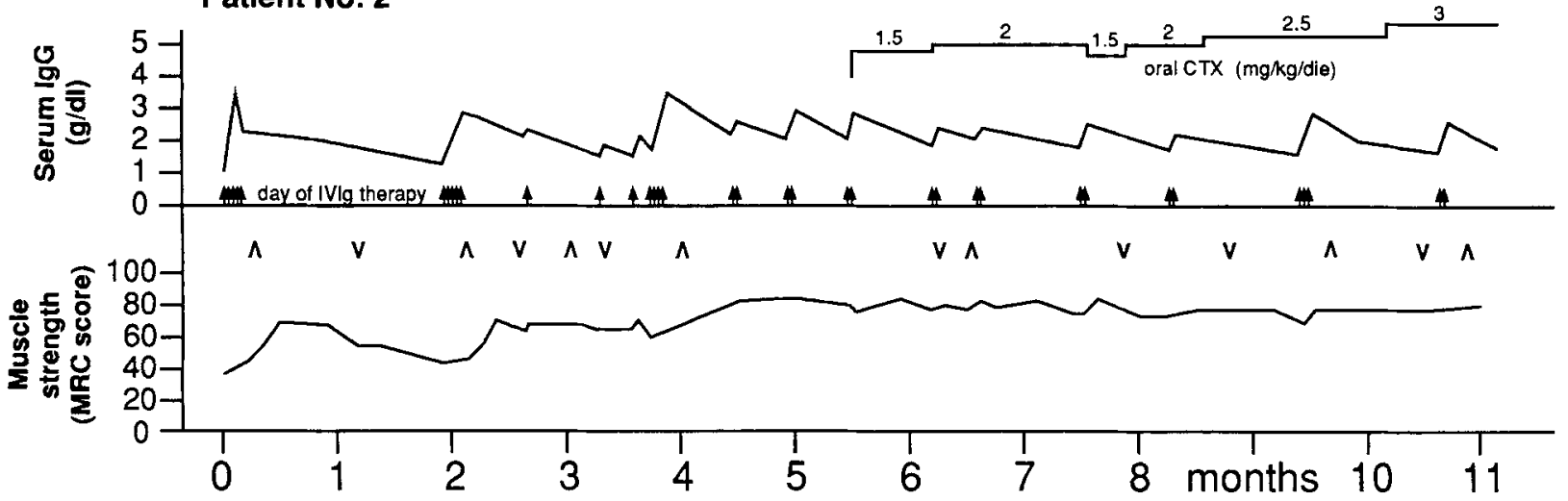

Figure 1. Clinical response to IVIg, expressed as the MRC score (the sum of the strength in the 10 most-affected muscles in upper and in lower limbs, total 20 muscles) in patients 1 and 2. Arrows indicate the day of IVIg infusions $(0.4 \mathrm{mg} / \mathrm{kg}$ each). The day when the patients started to improve $(A)$ or worsen $(v)$ is also indicated. After the addition of oral cyclophosphamide (CTX) the frequency of maintenance IVIg infusions could be progressively reduced.

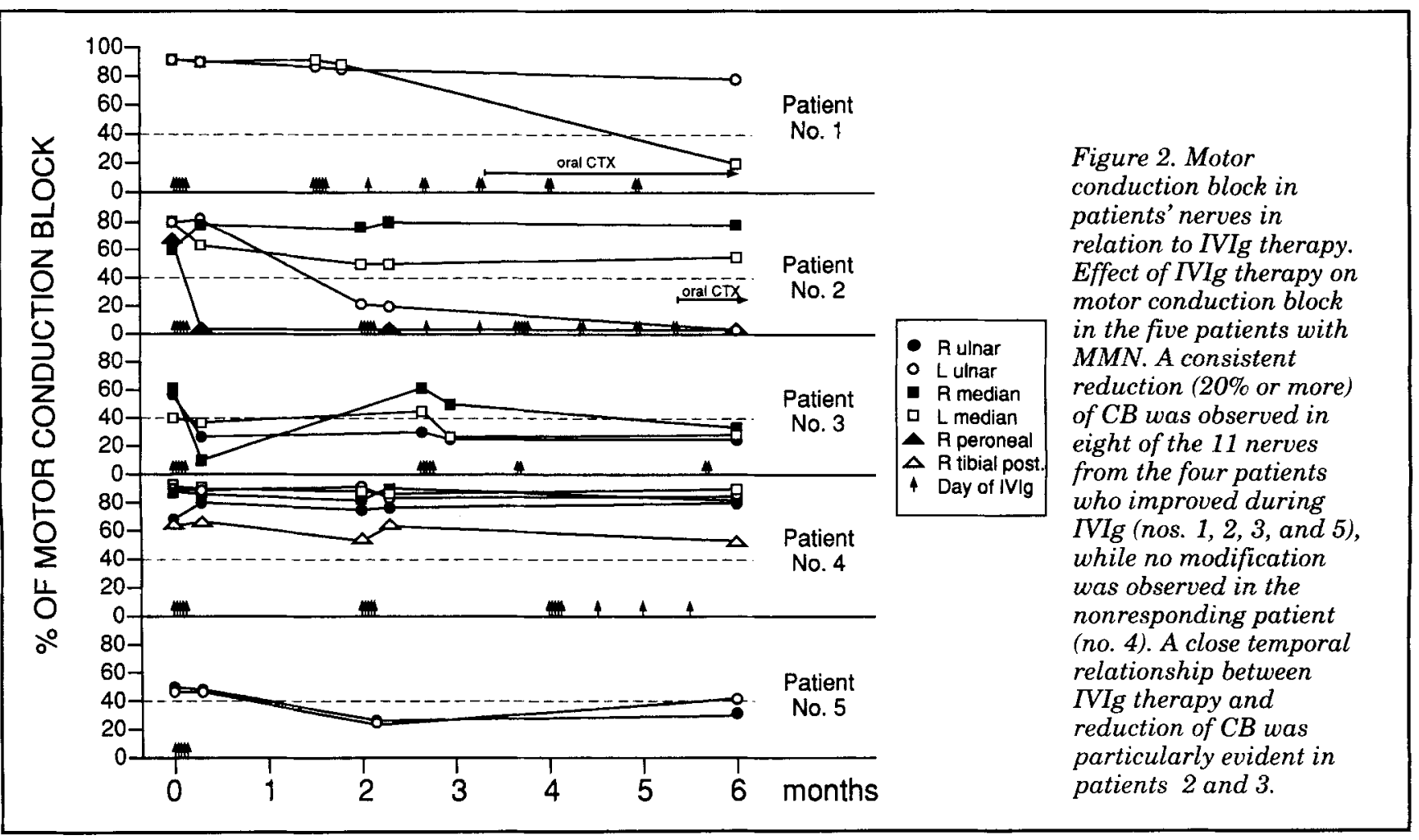




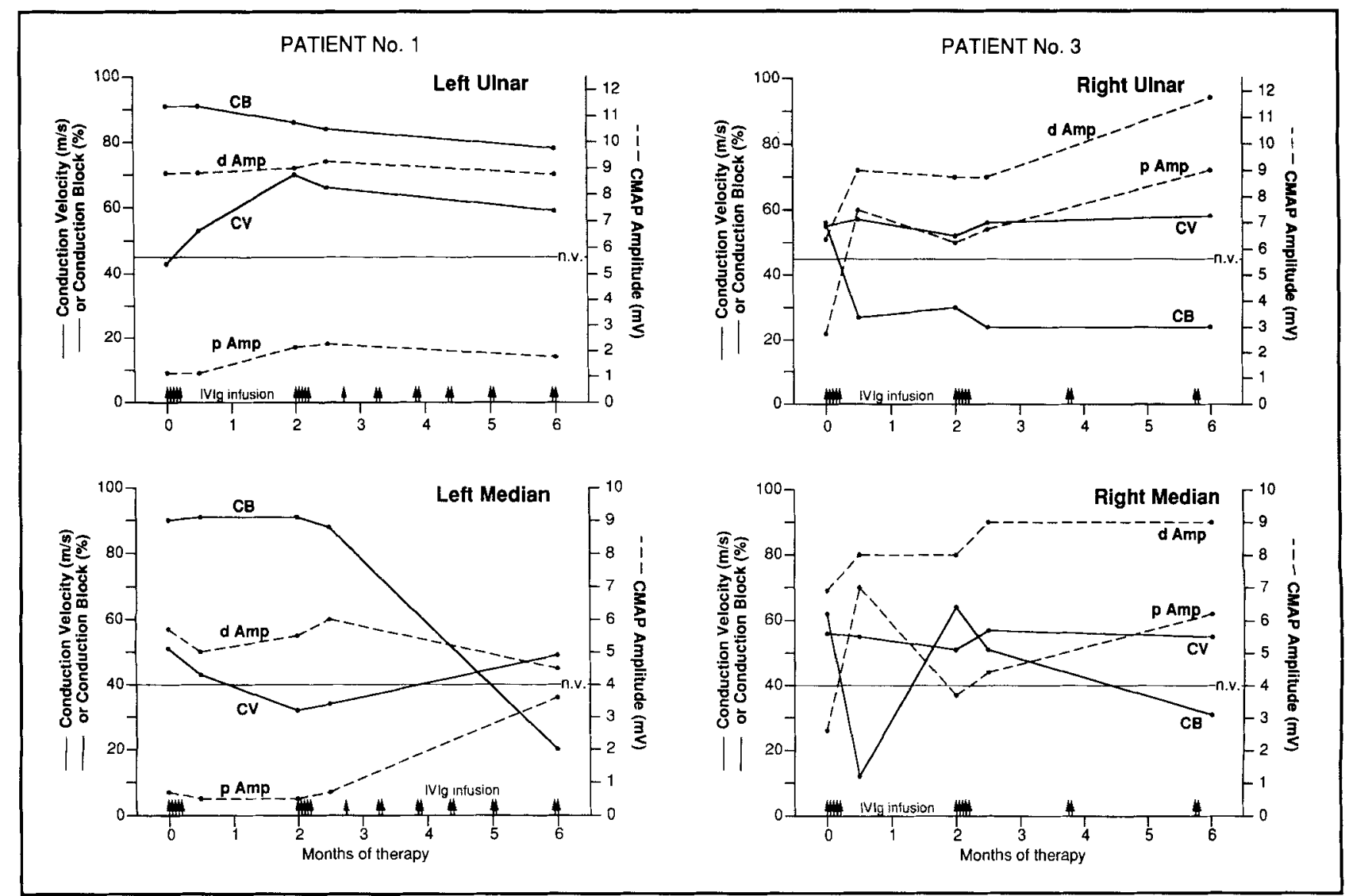

Figure 3. Effect of IVIg on the distal (d Amp) and proximal (p Amp) CMAP amplitude, motor conduction velocity (CV), and conduction block $(C B)$ in some representative nerves from patients 1 and 3 . No consistent variation of proximal and distal CMAP amplitudes was observed in the left ulnar of patient 1, while the reduction of CB in the left median nerve was due to a selective increase of proximal CMAP amplitude. In patient 3, the reduction of CB in the right ulnar and median nerves was associated with a concomitant increase of $p$ Amp and $d$ Amp. The lower normal limits if CMAP amplitude are indicated (n.v.)

months. In patient 3 , some fluctuations in antibody levels were observed during therapy, as reflected by the varying absorbances obtained when all serum samples were concomitantly tested, but they did not achieve the difference of a twofold serum dilution.

Discussion. Four of our five patients with MMN improved a few days after starting IVIg therapy. Improvement was more evident in the recently affected limb districts, while there was only minor or no effect on stabilized deficits. In one patient, recovery was complete and maintained without additional treatment for 12 months, while in three, improvement was temporary but was reproduced by a second course of IVIg and was maintained by periodic IVIg infusions for 8 to 12 months. The associated use of oral cyclophosphamide in two of these patients permitted us to progressively reduce the frequency of maintenance infusions. Clinical improvement in our patients was associated with reduction or resolution of motor CB in some, but not all, nerves, while there was no modification of $C B$ in the only patient that did not respond to IVIg therapy. Although the average improvement in the five patients after 6 months of therapy was only statistically significant for the MRC score and not for the Rankin and limb impairment scores, the close temporal relationship between IVIg therapy and improvement in both disability scales in four patients who had no previous spontaneous remission makes it unlikely that improvement was coincidental.

The beneficial, although usually temporary, effect of IVIg in our patients was similar to that reported in patients with CIDP ${ }^{15-20}$ and in other patients with MMN. ${ }^{29-32}$ The disease manifestations in our patients (as in other patients with MMN) ) $^{1-10}$ differed from typical CIDP. ${ }^{26,33}$ All our patients had an asymmetric weakness frequently associated with fasciculations and cramps, but only one patient had minor sensory impairment. The predominant electrodiagnostic feature was motor $\mathrm{CB}$ without widespread reduction of motor conduction velocities, ${ }^{23}$ and no patient had abnormal sensory conduction studies. Although these findings are more consistent with a focal than a diffuse demyelinating process, the frequent increase in the amplitude of distal CMAP in patients responding to IVIg therapy may reflect a concomitant, although less 
intense, diffuse demyelinating process also affecting distal nerve segments. ${ }^{22}$ As in most reported patients with $\mathrm{MMN}, 2,6,9$ in none of our patients was there morphologic evidence of a primary demyelinating process. In most of these patients, a sensory nerve was examined; evidence of demyelination with onion bulbs was found in the only patient in whom a proximal motor ulnar nerve biopsy was performed. ${ }^{8}$ Another distinguishing feature from CIDP was the lack of consistent increase of CSF proteins, as well as the frequent occurrence of anti-asialo- $\mathrm{GM}_{1}$ or, less frequently, $\mathrm{GM}_{1}$ antibodies, in our patients. Whether MMN is a variant of CIDP or a totally unrelated disease, however, is still a matter of debate. ${ }^{1-11,23}$

The mechanism of action of IVIg therapy is not fully understood, but it is current opinion that it interferes with the immune system, possibly explaining the beneficial effect in a number of immune diseases. ${ }^{34}$ The positive response to IVIg in our patients may therefore support the hypothesis that $\mathrm{MMN}$ is an immune-mediated disease, as also suggested by its frequent association with anti-ganglioside antibodies ${ }^{1-3}$ and by the concomitant improvement with decreasing anti-GM $\mathrm{GM}_{1}$ levels in some patients. ${ }^{2,11}$ Although all our responding patients had increased levels of anti-asialo-GM $\mathrm{GM}_{1}$ antibodies while no reactivity was present in the nonresponding patient, clinical improvement was not associated with a consistent decrease in antibody levels. It is therefore unlikely that IVIg therapy affected antibody synthesis or affinity, although it may have altered their binding capability or accessibility to antigen in vivo. Whether these antibodies have a pathogenetic role in MMN or merely represent an epiphenomenon with, possibly, a predictive value for response to therapy remains unclear.

The most important limiting factors for IVIg therapy are the elevated cost and transient effect, which make its continuous use very expensive for chronic diseases. This was partly overcome in our patients by the addition of low doses of oral cyclophosphamide that permitted reduction of the frequency of IVIg infusion. IVIg can be useful, therefore, in inducing a rapid response before low and possibly well-tolerated dosages of oral cytotoxic agents become effective. A controlled study on a larger group of patients is necessary to confirm these results.

\section{Acknowledgments}

We would like to thank Dr. G. Corbetta (Sandoz; Milan, Italy) for providing the human immunoglobulins at no cost for compassionate need treatment (Sandoglobulin; Sandoz; Basel, Switzerland). Dr. E. Scarpini referred one of the patients, and Drs. M. Moggio and M. Sciacco performed morphologic studies on nerve biopsies.

\section{References}

1. Pestronk A. Motor neuropathies, motor neuron disorders, and antiglycolipid antibodies. Muscle Nerve 1991;14:927-936.
2. Pestronk A, Cornblath DR, Ilyas A, et al. A treatable multi-focal motor neuropathy with antibodies to GM1 ganglioside. Ann Neurol 1988;24:73-78.

3. Pestronk A, Chaudhry V, Feldman EL, et al. Lower motor neuron syndromes defined by patterns of weakness, nerve conduction abnormalities, and high titers of antiglycolipid antibodies. Ann Neurol 1990;27:316-326.

4. Chad DA, Hammer K, Sargent J. Slow resolution of multifocal weakness and fasciculation: a reversible motor neuron syndrome. Neurology 1986;36:1260-1263.

5. Roth G, Rohr J, Magistris MR, Ochsner F. Motor neuropathy with proximal multifocal persistent conduction block, fasciculations and myokymia. Eur Neurol 1986;25:416-423.

6. Van den Bergh P, Logigian E, Kelly J.J. Motor neuropathy with multifocal conduction block. Muscle Nerve 1989;11:26-31.

7. Parry GH, Clarke S. Multifocal acquired demyelinating neuropathy masquerading as motor neuron disease. Muscle Nerve 1988;11:103-107.

8. Auer RN, Bell RB, Lee MA. Neuropathy with onion bulb formations and pure motor manifestations. Can J Neurol Sci 1989;16:194-197.

9. Krarup C, Stewart JD, Sumner AJ, Pestronk A, Lipton SA. A syndrome of asymmetric limb weakness with motor conduction block. Neurology 1990;40:118-127.

10. Bird SJ. Pure motor neuropathy. Curr Opin Neurology Neurosurgery 1990;3:704-707.

11. Feldman EL, Bromberg MB, Albers JW, Pestronk A. Immunosuppressive treatment in multifocal motor neuropathy. Ann Neurol 1991;30:397-401.

12. Calabresi P, Parks RE Jr. Antiproliferative agents and drugs used for immunosuppression. In: Goodman Gilman A, Goodman LS, Rall TW, Murad F, eds. The pharmacological basis of therapeutics, 7 th ed. New York: Macmillan, 1985:1247-1306.

13. Puri HC, Campbell RA. Cyclophosphamide and malignancy. Lancet $1977 ; 1: 1306$.

14. van der Meché FGA, Schmitz PIM, and the Dutch Guillain Barré Study Group. A randomized trial comparing intravenous immunoglobulin and plasma exchange in Guillain Barré syndrome. N Engl J Med 1992;326:1123-1129.

15. Vermeulen $M$, van der Meché FGA, Speelman JD, Weber A, Busch HFM. Plasma and gamma-globulin infusion in chronic inflammatory polyneuropathy. J Neurol Sci 1985;70:317-326.

16. Faed JM, Day B, Pollock M, Taylor PK, Nukada H, Hammond-Tooke GD. High-dose intravenous human immunoglobulin in chronic inflammatory demyelinating polyneuropathy. Neurology 1989;39:422-425.

17. Van Doorn PA, Brand A, Strengers PFW, Meulstee J, Vermeulen M. High-dose intravenous immunoglobulin treatment in chronic inflammatory demyelinating polyneuropathy: a double-blind, placebo-controlled, crossover study. Neurology 1990;40:209-212.

18. Van Doorn PA, Vermeulen M, Brand A, Mulder PGH, Busch HFM. Intravenous immunoglobulin treatment in patients with chronic inflammatory demyelinating polyneuropathy: clinical and laboratory characteristics associated with improvement. Arch Neurol 1991;48:217220.

19. Vettaikorumakankav V, Vedanarayanan V, Kandt RS, Lewis DW Jr, DeLong GR. Chronic inflammatory demyelinating polyradiculoneuropathy of childhood: treatment with high-dose intravenous immunoglobulin. Neurology 1991;41:828-830.

20. Cornblath DR, Chaudhry V, Griffin JW. Treatment of chronic inflammatory demyelinating polyneuropathy with intravenous immunoglobulin. Ann Neurol 1991;30:104106.

21. Van der Meché GA, Vermeulen M, Bush HFM. Chronic inflammatory demyelinating polyneuropathy: conduction failure before and during immunoglobulin or plasma therapy. Brain 1989;112:1563-1571.

22. Feasby T, Brown WF, Gilbert JJ, Hahn AF. The pathological basis of conduction block in human neuropathies. $J$ Neurol Neurosurg Psychiatry 1985;48:239-244. 
23. Lewis RA, Sumner AJ, Brown MJ, Asbury AK. Multifocal demyelinating neuropathy with persistent conduction block. Neurology 1982;32:958-964.

24. Nobile-Orazio E, Carpo M, Legname G, Meucci N, Sonnino $\mathrm{S}$, Scarlato G. Anti-GM $\mathrm{GIM}_{1}$ antibodies in motor neuron disease and neuropathy. Neurology 1990;40:1747-1750.

25. Medical Research Council. Aids to the investigation of peripheral nervous system. Memorandum no. 45. London: Her Majesty's Stationery Office, 1976.

26. Ad Hoc Subcommittee of the American Academy of Neurology AIDS Task Force. Research criteria for diagnosis of chronic inflammatory demyelinating polyneuropathy (CIDP). Neurology 1991;41:617-618.

27. Nobile-Orazio E, Marmiroli P, Baldini L, et al. Peripheral neuropathy in macroglobulinemia: incidence and antigenspecificity of M proteins. Neurology 1987;37:1506-1514.

28. Dyck PJ, Karnes J, Lais A, Lofgren EP, Stevens JK. Pathologic alteration of the peripheral nervous system of humans. In: Dyck PJ, Thomas PK, Lambert EH, Bunge R, eds. Peripheral neuropathy, 2nd ed. Philadelphia: WB Saunders, 1984:760-870.

29. Kaji R, Shibasaki H, Kimura J. Multifocal demyelinating motor neuropathy: cranial nerve involvement and immunoglobulin therapy. Neurology 1992;42:506-509.

30. Chaudhry V, Markl Corse A, Griffin JW, et al. Multifocal motor neuropathy with anti-GM1 antibodies and partial motor conduction block: favorable response to intravenous immunoglobulin therapy [abstract]. Neurology 1992;42(suppl 3):178.

31. Azulay JP, Blin $O$, Billé F, et al. High-dose intravenous human immunoglobulins are effective in the treatment of lower motor neuron syndromes associated with elevated serum anti-GM1 antibody titers: a double-blind, placebocontrolled study [abstract]. Neurology 1992;42(suppl 3):334.

32. Cros D, Siao P, Day B. High-dose immunoglobulin therapy (HIG) improves multifocal motor neuropathy with conduction blocks (MMNCB) and elevated anti-GM1 antibodies [abstract]. Neurology 1992;42(suppl 3):334.

33. Dyck PJ, Arnason B. Chronic inflammatory demyelinating polyneuropathy. In: Dyck PJ, Thomas PK, Lambert EH, Bunge R, eds. Peripheral neuropathy, 2nd ed. Philadelphia: WB Saunders, 1984:2101-2114.

34. Dwyer JM. Manipulating the immune system with immune globulin. N Engl J Med 1992;326:107-116.

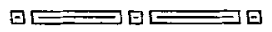

\title{
Low-dose apomorphine challenge in tardive akathisia
}

\author{
Perminder Sachdev, MD, PhD, FRANZCP, and Celia Loneragan, MA
}

Article abstract-We challenged seven tardive akathisia patients with low-dose apomorphine $(0.01 \mathrm{mg} / \mathrm{kg}) \mathrm{SC}$ and placebo in a double-blind, random design. Apomorphine caused a significantly greater reduction in the objective (movement) but not the subjective (distress) component of akathisia.

NEUROLOGY 1993;43:544-547

Tardive akathisia (TA) is a common disorder in patients chronically medicated with neuroleptics, ${ }^{1}$ but its pathophysiology is poorly understood and its treatment unsatisfactory. ${ }^{2}$ It differs from tardive dyskinesia (TD) in that the patient reports an abnormal subjective state in the form of feelings of distress and an aversion to remaining still. Unlike the choreoathetoid (typically oral-lingual-buccalfacial [OLBF]) movements of TD, the abnormal movements of TA are complex and stereotyped, and are particularly referable to the legs, giving the impression of restlessness with an inability to maintain posture for prolonged periods. There is some evidence pointing to the role of dopaminergic mechanisms in its pathophysiology: TA is described almost exclusively in patients treated with dopamine (DA)antagonist drugs ${ }^{2}$; most studies of TA have reported a strong overlap with TD, for which DA supersensitivity is still one of the major etiologic hypotheses ${ }^{3}$; and catecholamine-depleting drugs (eg, reserpine, tetrabenazine) may be beneficial in a number of patients. ${ }^{2}$ If $\mathrm{DA}$ overactivity is indeed involved in the causation of TA, drugs that reduce DA transmission should have an ameliorating effect. One such drug is apomorphine at low dose.

Apomorphine-HCl (APO) is a partial DA agonist that is presumed to have a biphasic effect on DA receptors: in large doses, it stimulates postsynaptic excitatory DA receptors, while small doses act preferentially on autoreceptors with resultant reduc- 


\section{Neurology}

High-dose intravenous immunoglobulin therapy in multifocal motor neuropathy

E. Nobile-Orazio, N. Meucci, S. Barbieri, et al.

Neurology 1993;43;537

DOI 10.1212/WNL.43.3_Part_1.537

\section{This information is current as of March 1, 1993}

Updated Information \&

Services

Citations

Permissions \& Licensing

Reprints including high resolution figures, can be found at:

http://n.neurology.org/content/43/3_Part_1/537.full

This article has been cited by 18 HighWire-hosted articles: http://n.neurology.org/content/43/3_Part_1/537.full\#\#otherarticles

Information about reproducing this article in parts (figures,tables) or in its entirety can be found online at:

http://www.neurology.org/about/about_the_journal\#permissions

Information about ordering reprints can be found online:

http://n.neurology.org/subscribers/advertise

Neurology ${ }^{\circledR}$ is the official journal of the American Academy of Neurology. Published continuously since 1951, it is now a weekly with 48 issues per year. Copyright $\odot 1993$ by Edgell Communications, Inc.. All rights reserved. Print ISSN: 0028-3878. Online ISSN: 1526-632X.

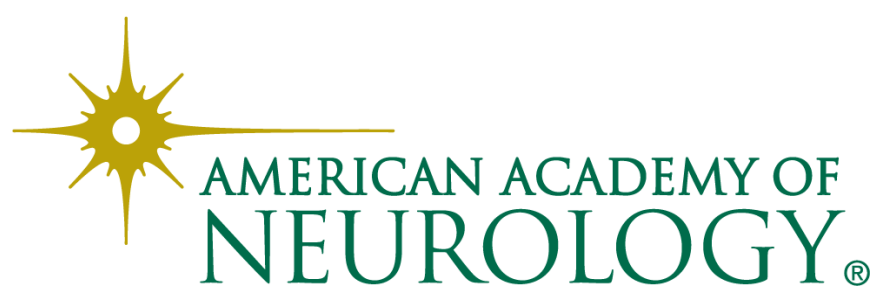

